\title{
Influence of disodium malate on microbial growth and fermentation in rumen-simulation technique fermenters receiving medium- and high-concentrate diets
}

\author{
J. A. Gómez, M. L. Tejido and M. D. Carro* \\ Departamento de Producción Animal I, Universidad de León, 24071 León, Spain
}

(Received 21 June 2004 - Revised 13 October 2004 - Accepted 1 November 2004)

\begin{abstract}
Two incubation trials were carried out with the rumen-simulation technique (RUSITEC). In each trial, four vessels received a diet of grass hay and concentrate (600 and $400 \mathrm{~g} / \mathrm{kg} \mathrm{DM}$, respectively; diet F), and the other four were fed a diet composed of concentrate and barley straw (900 and $100 \mathrm{~g} / \mathrm{kg} \mathrm{DM}$, respectively; Diet C). Vessels were given $20 \mathrm{~g}$ of the corresponding diet daily, and half of them were supplemented with disodium malate to achieve a final concentration of $6.55 \mathrm{mM}$. There were no effects $(P>0.05)$ of malate either on $\mathrm{pH}$ or on the daily production of $\mathrm{NH}_{3}-\mathrm{N}$, but malate treatment increased $(P<0.05) \mathrm{DM}$, neutral detergent and acid detergent fibre disappearance after $48 \mathrm{~h}$ incubation. The daily production of propionate and butyrate increased $(P<0 \cdot 001)$, and the ratio $\mathrm{CH}_{4}$ :volatile fatty acids decreased $(P<0 \cdot 001)$ by supplementing both diets with malate. Whereas adding malate to the $\mathrm{F}$ diet produced an increase in acetate production $(P=0.011)$ and the growth of solid-associated micro-organisms $(P=0 \cdot 037)$, no effects $(P>0 \cdot 05)$ were observed for diet $\mathrm{C}$. For both diets, there were no differences $(P>0.05)$ between treatments in the daily flow of liquid-associated micro-organisms measured using ${ }^{15} \mathrm{~N}$ as a microbial marker. These results indicate that malate stimulated the in vitro fermentation of both diets by increasing the apparent disappearance of the diet and decreasing the ratio of $\mathrm{CH}_{4}$ :volatile fatty acids, but a greater response was observed with diet $\mathrm{F}$. If these results are confirmed in vivo, malate could be used as a feed additive for ruminants fed diets containing medium proportions of forage (i.e. dairy animals) and not only in animals fed high-concentrate diets, as has so far been proposed.
\end{abstract}

Malate: Rumen fermentation: Microbial protein synthesis: RUSITEC

Organic acids (aspartate, malate, fumarate) have been suggested as an alternative to currently used antibiotic growth promoters (Newbold et al. 1996; Martin, 1998). Several papers (Martin \& Streeter, 1995; Callaway \& Martin, 1996; Carro et al. 1999; Carro \& Ranilla, 2003a; Martin, 2004) have shown that adding malate to in vitro fermentations of mixed rumen micro-organisms resulted in changes in the final $\mathrm{pH}, \mathrm{CH}_{4}$ and volatile fatty acids (VFA) that are analogous to ionophore effects. However, the results of some of these studies (Carro \& Ranilla, 2003a) indicate that the effects of malate are affected by the composition of the incubated diet. Most of the studies reported have been conducted in short-term experiments (incubations of up to $24 \mathrm{~h}$ ) using batch cultures of mixed rumen micro-organisms, and little is known about the longer-term effects of malate on in vitro rumen fermentation. Moreover, in these studies, single feeds (alfalfa hay, barley, wheat, maize, etc.) have been used as incubation substrates, and there are currently no studies available on the effects of malate on the in vitro rumen fermentation of diets representative of those fed to animals in practice.

In addition, research has shown that malate can stimulate the growth of Selenomonas ruminantium in pure cultures (Nisbet \& Martin, 1990, 1993), but no studies have been conducted to investigate the effects of malate on the growth of mixed rumen micro-organisms. The aim of the present study was therefore to investigate the long-term effects of disodium malate on the microbial growth and rumen fermentation of two different diets in rumen-simulation technique (RUSITEC) fermenters. Diets were formulated to be representative of those fed to dairy animals (diet F; medium-concentrate diet) and to growing ruminants under intensive systems of production (diet $\mathrm{C}$; high-concentrate diet).

\section{Materials and methods \\ Apparatus, diets and experimental procedure}

The complete unit of the RUSITEC consisted of eight vessels with an effective volume of $600 \mathrm{ml}$ each, and the general incubation procedure was as described by Czerkawski \& Breckenridge (1977). The inoculum was obtained from four ruminally fistulated sheep fed daily $500 \mathrm{~g}$ good-quality hay $(175 \mathrm{~g}$ crude protein and $476 \mathrm{~g}$ neutral detergent fibre (NDF) per $\mathrm{kg} \mathrm{DM}$ ) and $500 \mathrm{~g}$ commercial concentrate (164 g crude protein and $182 \mathrm{~g} \mathrm{NDF} / \mathrm{kg}$ DM). Sheep were managed according to the protocols approved by the León University Institutional Animal Care and Use Committee. Solid and liquid fermentation inocula were collected from sheep immediately before feeding and transferred to the in vitro system within $30 \mathrm{~min}$ as previously described (Carro et al. 1992). The flow through the vessels was maintained by a

\footnotetext{
Abbreviations: ADF, acid detergent fibre; LAM, lipid-associated micro-organisms; NAN, non- $\mathrm{NH}_{3}-\mathrm{N}$; NDF, neutral detergent fibre; RUSITEC, rumen-simulation technique; SAM, solid-associated micro-organisms; VFA, volatile fatty acids.

* Corresponding author: Dr M. D. Carro, fax +34 987 291311, email DP1MCT@UNILEON.ES
} 
continuous infusion of McDougall (1948) artificial saliva (pH 8.4) at a rate of $530 \mathrm{ml} / \mathrm{d}$ (dilution rate $3.7 \% / \mathrm{h}$ ). On day 9 , a dose of $2.18 \mathrm{mg}{ }^{15} \mathrm{~N}$ (95\% enriched $\left({ }^{15} \mathrm{NH}_{4}\right)_{2} \mathrm{SO}_{4}$; Sigma, Madrid, Spain) was added into each vessel to instantaneously label the $\mathrm{NH}_{3}$ - $\mathrm{N}$ pool. A solution of $\left({ }^{15} \mathrm{NH}_{4}\right)_{2} \mathrm{SO}_{4}$ was then added to the artificial saliva at a daily rate of $4.00 \mu \mathrm{g}{ }^{15} \mathrm{~N} / \mathrm{mg}$ dietary $\mathrm{N}$.

Two different diets were formulated, and each vessel received daily $20 \mathrm{~g}$ DM of the corresponding diet fed into nylon bags (100 $\mu \mathrm{m}$ pore size). Diet F consisted of grass hay and concentrate (600 and $400 \mathrm{~g} / \mathrm{kg} \mathrm{DM}$, respectively), and diet C was composed of concentrate and barley straw $(900$ and $100 \mathrm{~g} / \mathrm{kg}$ DM, respectively). The composition of both diets is shown in Table 1 . Grass hay and barley straw were chopped (to about $0.5 \mathrm{~cm}$ size), and concentrate components were ground through a $4 \mathrm{~mm}$ sieve and carefully mixed. Sugar beet molasses was added to the concentrates to allow a homogenous mix of the components. From the first day of incubation, four vessels in each incubation run were supplemented with malate (disodium salt; Sigma) to achieve a final concentration of $6.55 \mathrm{~mm}$, the other four vessels receiving no additive. Malate was weighed and carefully mixed with the concentrate before this was placed into the nylon bags.

Two identical incubation runs were carried out independently, and treatments were assigned randomly within each experimental run so that two vessels received each of the treatments; each treatment was, therefore, conducted in quadruplicate. Each incubation run consisted of $14 \mathrm{~d}$. After $8 \mathrm{~d}$ of adaptation, on days 9,10 and 11 , samples for gas, VFA and $\mathrm{NH}_{3}-\mathrm{N}$ determination were collected, and the apparent disappearance of diet was measured following the procedures described by Carro \& Miller (1999). On day 12 , the fluid vessel contents were sampled (about $1.5 \mathrm{ml}$ ) at $0,3,6,9$ and $12 \mathrm{~h}$ after feeding, the $\mathrm{pH}$ was immediately measured, and samples for VFA and $\mathrm{NH}_{3}-\mathrm{N}$ analysis were taken.

On days 12 and $13,5 \mathrm{ml}$ saturated $\mathrm{HgCl}_{2}$ were added (replacing the $\mathrm{H}_{2} \mathrm{SO}_{4}$ solution, which can cause bacterial lysis) to the overflow containers, which were held in an ice-water bath to impede microbial growth. For each vessel, the total effluent for days 12 and 13 was mixed and homogenised in a blender at low speed for $1 \mathrm{~min}$. One portion ( $300 \mathrm{~g})$ was frozen and lyophilised for determination of DM, non- $\mathrm{NH}_{3}-\mathrm{N}$ (NAN) and ${ }^{15} \mathrm{~N}$ enrichment, the rest of the mix being used to isolate liquid-associated micro-organisms (LAM). The contents of the nylon bags removed on days 12 and 13 were used to determine the growth of solid-associated

Table 1. Composition of basal diets incubated in the rumen-simulation technique system

\begin{tabular}{lcc}
\hline & Diet $\mathrm{F}$ & Diet C \\
\hline Ingredient composition (g/kg dry matter diet) & \\
Grass hay & 600 & - \\
Barley straw & - & 100 \\
Maize grains & 150 & 350 \\
Barley grains & 130 & 350 \\
Soyabean meal & 100 & 180 \\
Molasses, sugar beet & 10 & 10 \\
Mineral-vitamin mixture & 10 & 10 \\
Chemical composition (g/kg dry matter) & & 957 \\
Organic matter & 928 & 24.7 \\
Nitrogen & 25.5 & 220 \\
Neutral detergent fibre & 348 & 81.8 \\
Acid detergent fibre & 150 & 4.87 \\
Malate & $15 \cdot 1$ & 0.3675 \\
15 $\mathrm{N}$ (\% atoms) & 0.3678 & \\
\hline
\end{tabular}

micro-organisms (SAM). SAM pellets were isolated after treating one portion of the nylon bag contents (about $80 \%$ ) with a saline solution $\left(0.85 \% \mathrm{NaCl}\right.$; w/v) of methylcellulose $\left(0.1 \%\right.$; w/v) at $39^{\circ} \mathrm{C}$ as described by Ranilla \& Carro (2003). The remaining solid content (20\%) was lyophilised to determine DM, NAN and ${ }^{15} \mathrm{~N}$ enrichment. Microbial pellets were isolated by differential centrifugation as described by Carro \& Miller (1999). Diets were also analysed for their natural ${ }^{15} \mathrm{~N}$ content, and this value was used for background correction before ${ }^{15} \mathrm{~N}$ infusion.

Adaptive changes in the microbial population of the semi-continuous cultures to each treatment were studied using the vessels' fluid as inoculum for batch cultures and measuring the response in terms of final $\mathrm{pH}$ and production of VFA. The fermentative activity of the fluid contained in each vessel was tested against four pure substrates (all manufactured by Sigma): a mixture of starch ( $40 \mathrm{~g}$ wheat, $40 \mathrm{~g}$ barley and $200 \mathrm{~g}$ potato starch per kg mixture), oat spelt xylan, cellulose and pectin from citrus peel. On the last day of each incubation run, the two nylon bags present in the food container were removed and washed twice with $40 \mathrm{ml}$ the vessel's fluid, the washing liquid being returned to the vessel. Then $440 \mathrm{ml}$ fluid was mixed with $110 \mathrm{ml}$ artificial saliva (enriched with $1.09 \mathrm{~g} \mathrm{NH}_{4} \mathrm{Cl}$ per litre of saliva), and $50 \mathrm{ml}$ of the final mixture was anaerobically dispensed to $120 \mathrm{ml}$ serum bottles (Laboratorios Ovejero SA, León, Spain) containing $500 \mathrm{mg}$ of one of the substrates described earlier. Eight bottles (two bottles for each substrate) were incubated per each vessel. The bottles were sealed with rubber stoppers and $\mathrm{Al}$ caps, and incubated at $39^{\circ} \mathrm{C}$. After $6 \mathrm{~h}$ of incubation, the bottles were opened, the $\mathrm{pH}$ was immediately measured, and samples for VFA determination were taken as described earlier.

\section{Analytical procedures}

$\mathrm{DM}$, ash and $\mathrm{N}$ were determined according to the Association of Official Analytical Chemists (1995). NDF and acid detergent fibre (ADF) analyses were carried out according to the method of Van Soest et al. (1991). The concentration of $\mathrm{NH}_{3}$ was determined by a modified colorimetric method (Weatherburn, 1967). VFA were determined in centrifuged samples by GC as previously described (Carro et al. 1992). The volume of gas produced was measured with a drum-type gas meter (model TG1; Ritter Apparatebau $\mathrm{GmbH}$, Bochum, Germany), and the concentration of $\mathrm{CH}_{4}$ was analysed by chromatography as described by Carro \& Ranilla (2003b). The volume of gas $(1 / \mathrm{d})$ produced was corrected for standard conditions $\left(10^{5} \mathrm{~Pa}, 298 \mathrm{~K}\right)$, and the amount of $\mathrm{CH}_{4}$ produced (mmol/ d) was calculated by multiplying the gas produced by the $\mathrm{CH}_{4}$ concentration in the analysed sample. Preparation of samples for ${ }^{15} \mathrm{~N}$ analysis followed the procedures described by Carro \& Miller (1999), and analyses of ${ }^{15} \mathrm{~N}$ enrichment were performed by isotope ratio MS as described by Barrie \& Workman (1984). The preparation of feed samples for malate analysis and malate analysis by HPLC followed the procedures described by Callaway et al. (1997).

\section{Calculations and statistical analyses}

The proportion of digesta NAN (liquid or solid) of microbial origin was estimated for each vessel by dividing the ${ }^{15} \mathrm{~N}$ enrichment (atom \% excess) of the NAN portion of the digesta by the enrichment of the corresponding bacterial pellets (LAM or $\mathrm{SAM}$ ). Daily microbial $\mathrm{N}$ production $(\mathrm{mg} / \mathrm{d}$; LAM or $\mathrm{SAM})$ was estimated by multiplying the total NAN production in the 
corresponding digesta (liquid or solid) by the proportion attributed to the microbes. Total daily microbial production was calculated as the sum of the flows of LAM and SAM. The amounts of VFA produced in the batch cultures were obtained by subtracting the amounts initially present in the incubation medium from those determined at the end of the incubation period.

Data relative to fermentation parameters were analysed as a splitplot design using the general linear models procedures of the Statistical Analysis Systems program (version 6, 1989; SAS Institute Inc., Cary, NC, USA), with malate treatment as the main plot. The model included malate treatment, vessel nested within treatment, incubation trial, day of sampling, diet, and the treatment $\times$ diet interaction. The significance of malate effects was tested using the variance between vessels within treatment as the error term. The effects of other factors were tested against the residual error. In the analysis of data relative to microbial growth in the fermenters and to $\mathrm{pH}$ and VFA production in batch cultures, the day of sampling was excluded from the model. Time-sequence data on $\mathrm{pH}$, VFA and $\mathrm{NH}_{3}-\mathrm{N}$ concentrations in the liquid phase of the vessels were analysed within each time of sampling.

\section{Results}

There were no incidents during the course of the experiments, and the daily amount of effluent was not affected $(P>0.05)$ by malate treatment (553 and $555 \mathrm{ml} / \mathrm{d}$ for control and malate, respectively) or the incubated diet $(555$ and $553 \mathrm{ml} / \mathrm{d}$ for diets $\mathrm{F}$ and $\mathrm{C}$, respectively). The effects of malate treatment on $\mathrm{pH}$, diet disappearance and the daily production of VFA and $\mathrm{CH}_{4}$ are shown in Table 2 . The addition of malate did not affect $(P>0.05)$ rumen $\mathrm{pH}$ before feeding but increased the apparent disappearance of DM $(P=0.035), \mathrm{NDF}(P=0.028)$ and $\operatorname{ADF}(P=0.021)$ from the diet.

Compared with the control, the addition of malate increased $(P<0.001)$ the daily production of propionate $(2.45$ and $2.42 \mathrm{mmol} / \mathrm{d}$ increase for diets $\mathrm{F}$ and $\mathrm{C}$, respectively) and butyrate ( 0.99 and $2.00 \mathrm{mmol} / \mathrm{d}$ for diets $\mathrm{F}$ and $\mathrm{C}$, respectively) for both diets. Conversely, acetate production was only increased
$(P=0.011)$ for diet $\mathrm{F}(28.8$ and $31.8 \mathrm{mmol} / \mathrm{d}$ for control and malate treatments, respectively). The daily production of valerate and isovalerate was also increased $(P<0.05)$ by adding malate to both diets, but no effects $(P>0.05)$ on the production of isobutyrate were observed. As a consequence of these changes, adding malate increased $(P<0.05)$ total VFA production by 7.0 and in $5.9 \mathrm{mmol} / \mathrm{d}$ for diets $\mathrm{F}$ and $\mathrm{C}$, respectively. Supplementation with malate increased $(P<0.05)$ the concentration of VFA $(\mathrm{mmol} / \mathrm{d})$ at all sampling times for both diets (results not shown) but did not affect $(P>0.05)$ rumen $\mathrm{pH}$ and $\mathrm{NH}_{3}-\mathrm{N}$ concentration $(\mathrm{mg} / \mathrm{l})$ at any sampling time.

Adding malate did not affect $(P>0.05)$ the production of $\mathrm{CH}_{4}$ but decreased $\mathrm{CH}_{4}: \mathrm{DM}$ apparent disappearance (mmol/g; $P=0.001)$ and $\mathrm{CH}_{4}$ :VFA ratio (mmol $/ \mathrm{mmol} ; P=0.012$ ) for both diets (Table 2). As shown in Table 3, the daily flows of $\mathrm{NH}_{3}-\mathrm{N}$, total NAN and dietary NAN were not affected $(P>0.05)$ by the addition of malate, but microbial $\mathrm{N}$ flow tended to increase $(P=0.080)$ in the vessels supplemented with malate. This effect was due to the increase $(P=0.019)$ in the flow of SAM produced by malate $(13.3$ and $1.9 \mathrm{mg} / \mathrm{d}$ for diets $\mathrm{F}$ and $\mathrm{C}$, respectively) as there were no differences $(P>0.05)$ between treatments in the daily flow of LAM. Efficiency of microbial synthesis, calculated as mg microbial $\mathrm{N}$ per $\mathrm{g}$ DM apparent disappearance, was not affected $(P>0.05)$ by malate supplementation.

As expected, there were marked differences in rumen fermentation between diets. Rumen $\mathrm{pH}$ values and $\mathrm{NH}_{3}-\mathrm{N}$ concentrations were lower $(P<0.001)$ and VFA concentrations higher $(P<0.05)$ at all sampling times for vessels fed diet $\mathrm{C}$ than for those receiving diet $\mathrm{F}$. The disappearance of $\mathrm{DM}$ was greater $(P=0.001)$ and the $\mathrm{CH}_{4}$ :VFA ratio $(\mathrm{mmol} / \mathrm{mmol})$ lower $(P=0.001)$ for diet $\mathrm{C}$ than for diet $\mathrm{F}$, although the opposite was observed for SAM flow (41.3 and $60.5 \mathrm{mg} \mathrm{SAM}-\mathrm{N} / \mathrm{d}$ for diets $\mathrm{C}$ and F, respectively). There were no $(P>0.05)$ malate $\times$ diet interactions for any measured parameter.

The results of the in vitro incubations with batch cultures designed to detect possible changes in the fermentative activity

Table 2. Effects of malate $(6.55 \mathrm{~mm})$ on $\mathrm{pH}$ before feeding, apparent disappearance of diet after $48 \mathrm{~h}$ incubation and daily production of volatile fatty acid (VFA) and $\mathrm{CH}_{4}$ in a rumen-simulation technique system fed two different diets

(Values are the mean of three daily observations in each of four vessels; $n$ 12)

\begin{tabular}{|c|c|c|c|c|c|c|c|c|}
\hline \multirow[b]{2}{*}{ Item } & \multicolumn{2}{|c|}{ Diet $F^{\star}$} & \multicolumn{2}{|c|}{ Diet $C^{*}$} & \multirow[b]{2}{*}{ SED } & \multicolumn{3}{|c|}{ Significance level $(P=)$} \\
\hline & Control & Malate & Control & Malate & & Malate & Diet & Malate $\times$ diet \\
\hline $\mathrm{pH}$ & $6 \cdot 32$ & $6 \cdot 33$ & $5 \cdot 90$ & $5 \cdot 89$ & 0.017 & NS & 0.001 & NS \\
\hline \multicolumn{9}{|c|}{ Apparent disappearance (\%) of } \\
\hline DM & $62 \cdot 3$ & $64 \cdot 6$ & $64 \cdot 4$ & $65 \cdot 7$ & $1 \cdot 31$ & 0.035 & NS† & NS \\
\hline Neutral detergent fibre & $29 \cdot 7$ & 33.4 & $24 \cdot 1$ & $26 \cdot 0$ & 1.26 & 0.028 & 0.001 & NS \\
\hline Acid detergent fibre & 24.9 & $28 \cdot 4$ & $18 \cdot 8$ & $20 \cdot 2$ & 1.00 & 0.021 & 0.001 & NS \\
\hline \multicolumn{9}{|l|}{ VFA production $(\mathrm{mmol} / \mathrm{d})$} \\
\hline Acetate & $28 \cdot 8$ & 31.8 & $40 \cdot 3$ & $40 \cdot 8$ & 1.34 & NS & 0.001 & NS \\
\hline Propionate & 6.95 & $9 \cdot 40$ & $7 \cdot 88$ & $10 \cdot 3$ & 0.32 & 0.001 & 0.001 & NS \\
\hline Butyrate & $9 \cdot 21$ & $10 \cdot 2$ & $13 \cdot 1$ & $15 \cdot 1$ & 0.42 & 0.001 & 0.001 & NS \\
\hline Isobutyrate & 0.828 & 0.793 & 0.827 & 0.852 & 0.0884 & NS & NS & NS \\
\hline Valerate & 1.38 & 1.53 & 1.84 & $2 \cdot 21$ & 0.102 & 0.049 & 0.001 & NS \\
\hline Isovalerate & 3.05 & 3.50 & $3 \cdot 17$ & 3.76 & 0.089 & 0.007 & 0.013 & NS \\
\hline Total & $50 \cdot 2$ & $57 \cdot 2$ & $67 \cdot 1$ & $73 \cdot 0$ & 1.78 & 0.044 & 0.001 & NS \\
\hline $\mathrm{CH}_{4}(\mathrm{mmol} / \mathrm{d})$ & $12 \cdot 6$ & $12 \cdot 1$ & $13 \cdot 1$ & $12 \cdot 8$ & 0.44 & NS & NS & NS \\
\hline $\mathrm{CH}_{4}: \mathrm{DM}$ apparent & 1.011 & 0.936 & 1.017 & 0.972 & 0.0347 & 0.001 & NS & NS \\
\hline $\mathrm{CH}_{4}: \mathrm{VFA}(\mathrm{mmol}: \mathrm{mmol})$ & 0.251 & 0.212 & 0.195 & 0.175 & 0.0094 & 0.012 & 0.001 & NS \\
\hline
\end{tabular}

* Diet $F$ was composed of grass hay and concentrate (600 and $400 \mathrm{~g} / \mathrm{kg} \mathrm{DM}$, respectively) and diet $C$ was composed of barley straw and concentrate (100 and $900 \mathrm{~g} / \mathrm{kg} \mathrm{DM}$, respectively). $\mathrm{NS}^{\dagger} P<0.10$. 
Table 3. Effects of malate $(6.55 \mathrm{~mm})$ on daily production of $\mathrm{NH}_{3}-\mathrm{N}$ and non- $\mathrm{NH}_{3}-\mathrm{N}$ (NAN), microbial $\mathrm{N}$ flow and efficiency of microbial synthesis (mg microbial N/g DM apparent disappearance) in rumen-simulation technique system fed two different diets

(Values are the mean of three daily observations in each of four vessels $(n 12)$ for $\mathrm{NH}_{3}-\mathrm{N}$ and the mean of one observation in each of four vessels for the rest of parameters)

\begin{tabular}{|c|c|c|c|c|c|c|c|c|}
\hline \multirow[b]{2}{*}{ Item } & \multicolumn{2}{|c|}{ Diet } & \multicolumn{2}{|c|}{$\mathrm{F}^{\star}$} & \multirow[b]{2}{*}{ SED } & \multicolumn{3}{|c|}{ Significance level $(P=)$} \\
\hline & Control & Malate & Control & Malate & & Malate & Diet & Malate $\times$ diet \\
\hline $\mathrm{NH}_{3}-\mathrm{N}(\mathrm{mg} / \mathrm{d})$ & $120 \cdot 7$ & $121 \cdot 6$ & $115 \cdot 6$ & $115 \cdot 0$ & $2 \cdot 98$ & NS & NSt & NS \\
\hline Total NAN (mg/d) & 322 & 328 & 318 & 329 & $7 \cdot 42$ & NS & NS & NS \\
\hline Dietary NAN (mg/d) & 197 & 190 & 194 & 200 & $11 \cdot 0$ & NS & NS & NS \\
\hline Microbial $\mathrm{N}$ flow $(\mathrm{mg} / \mathrm{d})$ & 125 & 138 & 124 & 129 & 2.92 & NSt & NS & NS \\
\hline $\operatorname{LAM}(\mathrm{mg} / \mathrm{d})$ & 71.7 & $72 \cdot 3$ & $83 \cdot 7$ & $86 \cdot 7$ & $2 \cdot 96$ & NS & 0.015 & NS \\
\hline $\mathrm{SAM}(\mathrm{mg} / \mathrm{d})$ & $54 \cdot 1$ & $66 \cdot 8$ & $40 \cdot 3$ & $42 \cdot 2$ & $2 \cdot 18$ & 0.019 & 0.001 & NS \\
\hline SAM $(\%$ of total) & $43 \cdot 3$ & $48 \cdot 4$ & $32 \cdot 5$ & $32 \cdot 7$ & $2 \cdot 60$ & NS & 0.001 & NS \\
\hline Efficiency of microbial synthesis & $10 \cdot 1$ & $10 \cdot 8$ & 9.63 & $9 \cdot 81$ & 0.250 & NS & NSt & NS \\
\hline
\end{tabular}

LAM, lipid-associated micro-organisms; SAM, solid-associated micro-organisms.

${ }^{\star}$ Diet $\mathrm{F}$ was composed of grass hay and concentrate $(600$ and $400 \mathrm{~g} / \mathrm{kg} \mathrm{DM}$, respectively) and diet $\mathrm{C}$ was composed of barley straw and concentrate (100 and $900 \mathrm{~g} / \mathrm{kg}$ DM, respectively).

$\mathrm{NS}^{\dagger} P<0 \cdot 10$.

of the semi-continuous cultures in response to the addition of malate are shown in Table 4. For all substrates, there was no difference $(P>0.05)$ between the control vessels and those supplemented with malate in terms of the final $\mathrm{pH}$ after $6 \mathrm{~h}$ incubation. Batch cultures inoculated with rumen fluid from vessels supplemented with malate produced greater $(P<0.001)$ amounts of VFA with cellulose and tended $(P=0.071)$ to produce greater amounts of VFA with xylan. With all substrates, the final $\mathrm{pH}$ was lower $(P<0.001)$ in batch cultures inoculated with fluid from vessels fed diet $\mathrm{F}$ than in those corresponding to vessels fed diet $\mathrm{C}$. There were, however, no interactions $(P>0.05)$ between malate supplementation and diet for any parameter.

\section{Discussion}

In the past few years, several papers have investigated the effects of malate on rumen $\mathrm{pH}$ in batch cultures (Martin \& Streeter, 1995; Callaway \& Martin, 1996; Carro \& Ranilla, 2003a; Martin, 2004) and semi-continuous fermenters (Carro et al. 1999), but the results reported are contradictory. Whereas concentrations of malate ranging from 7 to $12 \mathrm{~mm}$ consistently increased the final $\mathrm{pH}$ in batch cultures containing hay or different concentrate feeds (Martin \& Streeter, 1995; Callaway \& Martin, 1996; Carro \& Ranilla, 2003a; Martin, 2004), no effects of $8.0 \mathrm{~mm}$ malate were reported in semi-continuous fermenters fed a diet containing $500 \mathrm{~g}$ alfalfa hay and $500 \mathrm{~g}$ concentrate per $\mathrm{kg}$ (Carro et al. 1999). The latter results agree with those observed in the present experiment and could be explained by the high buffer capacity of the artificial saliva used in the fermenters. In fact, rumen $\mathrm{pH}$ remained fairly stable through the day for both diets.

The increased daily VFA production observed with both diets in this experiment is in agreement with previously reported results. Increases in the production of acetate, propionate and butyrate have been reported when batch cultures containing different concentrate feeds (maize, barley, wheat and sorghum) were supplemented with $7 \mathrm{~mm}$ and $10 \mathrm{~mm}$ malate (Carro \& Ranilla, 2003a), although Carro et al. (1999), in semi-continuous fermenters fed a mixed diet $(500 \mathrm{~g}$ alfalfa hay $/ \mathrm{kg})$, found that

Table 4. Final $\mathrm{pH}$ and production of volatile fatty acid (VFA) in batch cultures containing $500 \mathrm{mg}$ different substrates (starch, cellulose, xylan and pectin) after $6 \mathrm{~h}$ incubation with vessels fluid from rumen-simulation technique fermenters fed two different diets and supplemented daily with or without $6.55 \mathrm{~mm}$-malate

(Mean values of eight fermentations)

\begin{tabular}{|c|c|c|c|c|c|c|c|c|}
\hline \multirow[b]{2}{*}{ Substrate and item } & \multicolumn{2}{|c|}{ Diet $F^{\star}$} & \multicolumn{2}{|c|}{ Diet } & \multirow[b]{2}{*}{ SED } & \multicolumn{3}{|c|}{ Significance level $(P=)$} \\
\hline & Control & Malate & Control & Malate & & Malate & Diet & Malate $\times$ diet \\
\hline \multicolumn{9}{|l|}{ Starch } \\
\hline $\mathrm{pH}$ & 5.52 & 5.59 & $5 \cdot 67$ & $5 \cdot 68$ & 0.022 & NS & 0.001 & NS \\
\hline VFA $(\mu \mathrm{mol})$ & 3624 & 3581 & 3701 & 3615 & $107 \cdot 4$ & NS & NS & NS \\
\hline \multicolumn{9}{|l|}{ Cellulose } \\
\hline $\mathrm{pH}$ & $6 \cdot 37$ & $6 \cdot 42$ & 6.63 & 6.65 & 0.014 & NS & 0.001 & NS \\
\hline VFA $(\mu \mathrm{mol})$ & 591 & 834 & 490 & 679 & $83 \cdot 9$ & 0.001 & NS & NS \\
\hline \multicolumn{9}{|l|}{ Xylan } \\
\hline $\mathrm{pH}$ & $6 \cdot 18$ & $6 \cdot 19$ & $6 \cdot 41$ & $6 \cdot 30$ & 0.046 & NS & 0.001 & NS \\
\hline VFA $(\mu \mathrm{mol})$ & 1531 & 1924 & 1395 & 1596 & $118 \cdot 7$ & NSt & 0.011 & NS \\
\hline \multicolumn{9}{|l|}{ Pectin } \\
\hline $\mathrm{pH}$ & $5 \cdot 84$ & $5 \cdot 88$ & 5.99 & 6.05 & 0.026 & NS & 0.001 & NS \\
\hline VFA $(\mu \mathrm{mol})$ & 3144 & 3087 & 2233 & 2599 & $145 \cdot 7$ & NS & 0.001 & NS \\
\hline
\end{tabular}

* Diet $\mathrm{F}$ was composed of grass hay and concentrate $(600$ and $400 \mathrm{~g} / \mathrm{kg} \mathrm{DM}$, respectively) and diet $\mathrm{C}$ was composed of barley straw and concentrate (100 and $900 \mathrm{~g} / \mathrm{kg} \mathrm{DM}$, respectively).

$\mathrm{NS}^{\dagger} P<0.10$ 
adding $8 \mathrm{~mm}$ malate increased the daily production of propionate, but did not affect $(P>0.05)$ the production of acetate or butyrate. These contrasting results could indicate that the effects of malate depend on the incubated diet, and the results of the present study seem to support this hypothesis.

Although malate increased VFA production with both diets, there were some differences in the observed response. Whereas the increase in propionate production was similar for diets $\mathrm{F}$ and $\mathrm{C}(2.45$ and $2.42 \mathrm{mmol} / \mathrm{d}$, respectively), the increase in acetate and butyrate production was distinct: 3.04 and $0.53 \mathrm{mmol}$ acetate/d and 0.99 and $2.00 \mathrm{mmol}$ butyrate/d for diets $\mathrm{F}$ and $\mathrm{C}$, respectively. As a consequence of the changes in the individual VFA, adding malate at $6.55 \mathrm{~mm}$ (which represents $3.93 \mathrm{mmol}$ malate per vessel daily) increased total VFA production by $7.0 \mathrm{mmol} / \mathrm{d}$ for diet $\mathrm{F}$ and in $5.9 \mathrm{mmol} / \mathrm{d}$ for diet $\mathrm{C}$. These results indicate that the observed increase in VFA production could not only stem from malate fermentation itself as it has been reported that malate can be converted into propionate and acetate following different pathways (Demeyer \& Henderickx, 1967). The observed increase in the apparent disappearance of the diet (see Table 2) is in agreement with the greater production of VFA and suggests that malate stimulated the in vitro fermentation of both diets.

The fact that malate supplementation increased the concentration of VFA at 3, 6, 9 and $12 \mathrm{~h}$ after feeding for both diets also indicates a stimulatory effect of malate on fermentation, presumably due to changes in bacterial populations and/or in their activity. Nisbet \& Martin (1990, 1993) showed that adding malate to in vitro cultures stimulated the growth of Selenomonas ruminantium in a medium that contained lactate, but to our knowledge no information about the effects of malate on the in vitro growth of mixed-rumen micro-organisms is available. We therefore decided to measure the growth of SAM and LAM in the present experiment. Adding $6.55 \mathrm{~mm}$ malate increased $(P=0.037)$ the growth of SAM in $12.5 \mathrm{mg}$ SAM-N/d for diet $\mathrm{F}$, but no significant $(P>0.05)$ effect was observed for diet $\mathrm{C}$. The greater SAM growth observed for diet $\mathrm{F}$ agrees with the reported increase in apparent disappearance of NDF and ADF. These results are in accordance with those from previous research conducted in our laboratory (García-Martínez et al. 2004), which showed that $8 \mathrm{mM}$-malate increased the growth of rumen microorganisms in batch cultures with a high-forage diet $(800 \mathrm{~g}$ forage $/ \mathrm{kg}$ ), but no effect was observed with medium- or lowforage diets ( 500 or $200 \mathrm{~g}$ forage $/ \mathrm{kg}$, respectively). Other authors have reported increases in the number of cellulolytic bacteria in sheep fed malate (Newbold et al. 1996) and in RUSITEC fermenters supplemented with fumarate (López et al. 1999). All these results seem to indicate that malate and fumarate can have a stimulatory effect on rumen microbial growth, but this effect can be influenced by diet and experimental conditions.

In the present experiment, the differences observed between diets in the fermentation pattern $(\mathrm{pH}$, production of VFA, disappearance of NDF, etc.) would indicate that a different microbial population was established in the vessels fed the two diets. The $\mathrm{pH}$ values in vessels fed diet $\mathrm{C}$ ranged from 5.84 to 6.00, and it has been reported that cellulolytic bacteria failed to grow at a $\mathrm{pH}$ of less than 6.0 (Stewart, 1977). That could explain the lower apparent disappearance of NDF and $\operatorname{ADF}(P=0.001)$ observed for diet $\mathrm{C}$ compared with diet $\mathrm{F}$ (see Table 2), although the differences between both diets in fibre composition should also be taken into account. Nevertheless, the increase in disappearance of NDF and ADF observed by adding malate to both diets would indicate that one of the beneficial effects of malate may be to increase fibre digestion, as has been previously observed by Carro et al. (1999) in semi-continuous fermenters and by Newbold et al. (1996) in sheep.

As expected, the mean proportion of SAM-N in the particulate fraction of the fermenters (nylon bag residues) was greater $(P=0.001)$ for diet $\mathrm{F}(45.8 \%)$ than for diet $\mathrm{C}(32.6 \%)$. This proportion was not affected $(P>0.05)$ by adding malate to diet $\mathrm{C}$, but malate tended $(P=0 \cdot 10)$ to increase it for diet $\mathrm{F}$, which agrees with the increased disappearance of the diet observed for malate-supplemented vessels fed this diet. For both diets, the growth of LAM was not affected $(P>0.05)$ by adding malate. Malate was mixed with the concentrate portion of the diet, and, due to the high compartmentation in the RUSITEC system, it is possible that it had been completely fermented by SAM. Although malate disappearance was not measured in the present experiment, Russel \& Van Soest (1984) indicated that $7.5 \mathrm{~mm}$ malate was fermented in vitro within $10 \mathrm{~h}$, and Callaway \& Martin (1997) found that $7.5 \mathrm{~mm}$-malate disappeared within $24 \mathrm{~h}$ in batch cultures. The level of malate used in our experiment $(6.55 \mathrm{mM})$ would justify the assumption that the amount of malate added daily was completely fermented in $24 \mathrm{~h}$. Therefore, the differences observed in the in vitro incubations with batch cultures using vessel fluid as the inoculum can only be due to changes in the microbial population of the semi-continuous cultures produced by the addition of malate.

There were, however, only subtle effects of inocula (fluid from malate-supplemented vessels compared with that from unsupplemented vessels) on the in vitro fermentation. The greater VFA production $(P=0.001)$ observed when cellulose was incubated with fluid from malate-supplemented vessels would indicate a greater fibrolytic activity of the incubation medium, and this observation is in agreement with the trend $(P=0.071)$ towards a greater VFA production observed for xylan when it was incubated with fluid from the malate-supplemented vessels. The greater apparent disappearance of NDF and ADF observed in RUSITEC fermenters by adding malate to the diet would support this hypothesis. Nonetheless, it must be taken into account that since only the vessels' fluid was used as inoculum, any effect of malate on the SAM population could not be detected in the batch cultures' trial. Both LAM and the non-adherent microorganisms washed out of the solid (nylon bags being washed twice with $40 \mathrm{ml}$ of the vessels' fluid, with the washing liquid returned to the vessel before using the fluid as inoculum for the batch cultures' incubations) should have been present in the vessels' fluid. However, SAM and the non-adherent population have been reported to be responsible for most of the feed digestion in the rumen (McAllister et al. 1994), and this can explain that only subtle effects of inoculum were observed in batch cultures compared with the greater differences in diet disappearance found in RUSITEC fermenters.

In agreement with the results reported by Carro et al. (1999), malate did not affect $(P>0.05)$ the daily production of $\mathrm{CH}_{4}$ but decreased $(P<0.05)$ the apparent disappearance of $\mathrm{CH}_{4}: \mathrm{DM}$ (mmol/g) and the $\mathrm{CH}_{4}$ :VFA ratio $(\mathrm{mmol} / \mathrm{mmol})$ for both diets (see Table 2). The observed decrease in $\mathrm{CH}_{4}$ production $(4.1 \%$ and $2.3 \%$ for diets $\mathrm{F}$ and $\mathrm{C}$, respectively) is in the range of previously reported results for similar doses of malate (Callaway \& Martin, 1996; Carro \& Ranilla, 2003a; Tejido et al. 2005), and, as has been suggested by other authors for fumarate 
(López et al. 1999), malate would be impractical as a means of reducing $\mathrm{CH}_{4}$ emissions in vivo. $\mathrm{CH}_{4}$ production is affected by many factors, such as the type of diet and the rumen $\mathrm{pH}$. The daily $\mathrm{CH}_{4}$ production values, expressed as $\mathrm{mmol} / \mathrm{g}$ DM diet apparent disappearance, ranged from 0.936 to 1.017 , and were

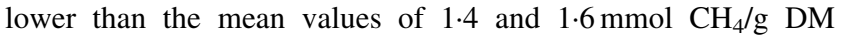
degraded reported by Czerkawski (1986) for concentrate and mixed diets, respectively. Russell (1998) showed that $\mathrm{CH}_{4}$ production in vitro decreased dramatically at $\mathrm{pH}$ values below 6.5, and in our experiment rumen $\mathrm{pH}$ was always below $6 \cdot 3$ (results not shown), which can explain the low $\mathrm{CH}_{4}$ production. Our values were in the range of those previously reported in continuous fermenters fed diets differing in their forage:concentrate ratio and maintained at a $\mathrm{pH}$ of less than $6 \cdot 3$ (Eun et al. 2004).

The results of the present study indicate that malate was effective in increasing diet degradation and VFA production for both diets, although a greater response was observed for diet $\mathrm{F}$ in comparison with diet $\mathrm{C}$. If these results are confirmed in vivo, malate could be used as additive in ruminants fed medium proportions of forage (i.e. dairy animals) and not only in animals fed high-concentrate diets, as has been proposed up to now.

\section{Acknowledgements}

The authors wish to acknowledge the financial support received from the CICYT (Project AGL2001-0130) and Junta de Castilla y León (Project LE62/03). Analyses of ${ }^{15} \mathrm{~N}$ isotope ratios were performed at the Servicio Interdepartamental de Investigación of the Universidad Autónoma de Madrid, Spain.

\section{References}

Association of Official Analytical Chemists (1995) Official Methods of Analysis, 16th edn, Arlington, VA: AOAC.

Barrie S \& Workman CT (1984) An automated analytical system for nutritional investigations using N-15 tracers. Spectrosc-In J 3, 439-447.

Callaway TR \& Martin SA (1996) Effects of organic acid and monensin treatment on in vitro mixed ruminal microorganism fermentation of cracked corn. J Anim Sci 74, 1982-1989.

Callaway TR \& Martin SA (1997) Effects of cellobiose and monensin on in vitro fermentation of organic acids by mixed ruminal bacteria. J Dairy Sci 80, 1126-1135.

Callaway TR, Martin SA, Wampler JL, Hill NS \& Hill GM (1997) Malate content of forage varieties commonly fed to cattle. J Dairy Sci 80, $1651-1655$.

Carro MD \& Miller EL (1999) Effect of supplementing a fibre basal diet with different nitrogen forms on ruminal fermentation and microbial growth in an in vitro semicontinuous culture system (RUSITEC). Br J Nutr 82, 149-157.

Carro MD \& Ranilla MJ (2003a) Effect of the addition of malate on in vitro rumen fermentation of cereal grains. Br J Nutr 89, 279-288.

Carro MD \& Ranilla MJ (2003b) Influence of different concentrations of disodium fumarate on methane production and fermentation of concentrate feeds by rumen microorganisms in vitro. Br J Nutr 90, 617-623.

Carro MD, Lebzien P \& Rohr K (1992) Influence of yeast culture on the in vitro fermentation (Rusitec) of diets containing variable portions of concentrates. Anim Feed Sci Technol 37, 209-220.

Carro MD, López S, Valdés C \& Ovejero FJ (1999) Effect of DL-malate on mixed ruminal microorganism fermentation using the rumen simulation technique (RUSITEC). Anim Feed Sci Technol 79, 279-288.

Czerkawski JW (1986) An Introduction to Rumen Studies. Oxford: Pergammon Press.

Czerkawski JW \& Breckenridge G (1977) Design and development of a long-term rumen simulation technique (Rusitec). Br J Nutr 38, 371-384.

Demeyer DI \& Henderickx MK (1967) Competitive inhibition of in vitro methane production by mixed rumen bacteria. Arch Int Phys Bioch 75, $157-159$.

Eun J-S, Fellner V \& Gumpertz ML (2004) Methane production by mixed ruminal cultures incubated in dual-flow fermenters. J Dairy Sci 87, $112-121$

López S, Valdés C, Newbold CJ \& Wallace RJ (1999) Influence of sodium fumarate addition on rumen fermentation in vitro. Br J Nutr 81, 59-64.

McAllister TA, Bae HD, Jones GA \& Cheng KJ (1994) Microbial attachment and feed digestion in the rumen. J Anim Sci 72, 3004-3018.

McDougall EI (1948) Studies on ruminant saliva. I. The composition and output of sheep's saliva. Biochem J 43, 99-109.

Martin SA (1998) Manipulation of ruminal fermentation with organic acids: a review. J Anim Sci 76, 3123-3132.

Martin SA (2004) Effects of DL-malate on in vitro forage fiber digestion by mixed ruminal microorganisms. Curr Microbiol 48, 27-31.

Martin SA \& Streeter MN (1995) Effect of malate on in vitro mixed ruminal microorganism fermentation. J Anim Sci 73, 2141-2145.

Newbold CJ, Wallace RJ \& McIntosh FM (1996) Mode of action of the yeast Saccharomyces cerevisiae as a feed additive for ruminants. $\mathrm{Br}$ J Nutr 76, 249-261.

Nisbet DJ \& Martin SA (1990) Effect of dicarboxylic acids and Aspergillus oryzae fermentation extract on lactate uptake by the ruminal bacterium Selenomonas ruminantium. Appl Environ Microb 56, 3515-3518.

Nisbet DJ \& Martin SA (1993) Effects of fumarate, L-malate, and an Aspergillus oryzae fermentation extract on D-lactate utilization by the ruminal bacterium Selenomonas ruminantium. Curr Microbiol 26, $133-136$.

Ranilla MJ \& Carro MD (2003) Diet and procedures to detach particleassociated microbes from ruminal digesta influence chemical composition of microbes and estimation of microbial growth in Rusitec fermenters. J Anim Sci 81, 537-544.

Russell JB (1998) The importance of $\mathrm{pH}$ in the regulation of ruminal acetate to propionate ratio and methane production in vitro. J Dairy Sci $\mathbf{8 1}$, 3222-3230.

Russell JB \& Van Soest PJ (1984) In vitro ruminal fermentation of organic acids common in forage. Appl Environ Microb 47, 155-159.

Stewart CS (1977) Factors affecting cellulolytic activity of rumen contents. Appl Environ Microb 33, 497-502.

Tejido ML, Ranilla MJ, García-Martinez R \& Carro MD (2005) In vitro microbial growth and rumen fermentation of diets differing their forage:concentrate ratio as affected by the addition of disodium malate. Anim Sci (In the press).

Van Soest PJ, Robertson JB \& Lewis BA (1991) Methods for dietary fiber, neutral detergent fiber, and nonstarch polysaccharides in relation to animal nutrition. J Dairy Sci 74, 3583-3597.

Weatherburn MW (1967) Phenol-hypochlorite reaction for determination of ammonia. Anal Chem 39, 971-974. 